Hydrol. Earth Syst. Sci., 14, 193-204, 2010

www.hydrol-earth-syst-sci.net/14/193/2010/

(C) Author(s) 2010. This work is distributed under

the Creative Commons Attribution 3.0 License.

\title{
Relating surface backscatter response from TRMM precipitation radar to soil moisture: results over a semi-arid region
}

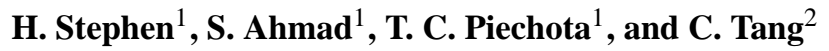 \\ ${ }^{1}$ Department of Civil and Environmental Engineering, University of Nevada, Las Vegas, NV 89154, USA \\ ${ }^{2}$ Department of Geosciences, Idaho State University, Pocatello, ID 83209, USA
}

Received: 5 October 2009 - Published in Hydrol. Earth Syst. Sci. Discuss.: 22 October 2009

Revised: 15 January 2010 - Accepted: 19 January 2010 - Published: 5 February 2010

\begin{abstract}
The Tropical Rainfall Measuring Mission (TRMM) carries aboard the Precipitation Radar (TRMMPR) that measures the backscatter $\left(\sigma^{\circ}\right)$ of the surface. $\sigma^{\circ}$ is sensitive to surface soil moisture and vegetation conditions. Due to sparse vegetation in arid and semi-arid regions, TRMMPR $\sigma^{\circ}$ primarily depends on the soil water content. In this study we relate TRMMPR $\sigma^{\circ}$ measurements to soil water content $\left(m_{s}\right)$ in the Lower Colorado River Basin (LCRB). $\sigma^{\circ}$ dependence on $m_{s}$ is studied for different vegetation greenness values determined through Normalized Difference Vegetation Index (NDVI). A new model of $\sigma^{\circ}$ that couples incidence angle, $m_{s}$, and NDVI is used to derive parameters and retrieve soil water content. The calibration and validation of this model are performed using simulated and measured $m_{s}$ data. Simulated $m_{s}$ is estimated using the Variable Infiltration Capacity (VIC) model and measured $m_{s}$ is acquired from ground measuring stations in Walnut Gulch Experimental Watershed (WGEW).

$\sigma^{\circ}$ model is calibrated using VIC and WGEW $m_{s}$ data during 1998 and the calibrated model is used to derive $m_{s}$ during later years. The temporal trends of derived $m_{s}$ are consistent with VIC and WGEW $m_{s}$ data with a correlation coefficient $(R)$ of 0.89 and 0.74 , respectively. Derived $m_{s}$ is also consistent with the measured precipitation data with $R=0.76$. The gridded VIC data is used to calibrate the model at each grid point in LCRB and spatial maps of the model parameters are prepared. The model parameters are spatially coherent with the general regional topography in LCRB. TRMMPR $\sigma^{\circ}$ derived soil moisture maps during May (dry) and August (wet) 1999 are spatially similar to VIC estimates with correlation
\end{abstract}

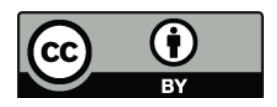

Correspondence to: S. Ahmad (sajjad.ahmad@unlv.edu)
0.67 and 0.76 , respectively. This research provides new insights into Ku-band $\sigma^{\circ}$ dependence on soil water content in the arid regions.

\section{Introduction}

The ongoing drought of the Colorado River Basin in the southwestern United States started in 2000 and has become the longest drought in the recorded history of the basin (Timilsena et al., 2007). This is evident from the historic low levels in most of the storage lakes that has resulted in severe water shortage in some user states. The Colorado River Basin provides water to seven states in the US and Mexico. Due to the regional importance of this basin and agricultural and social impacts of water scarcity, it is important to understand the factors related to droughts. Timely information of possible drought can improve decisions for water management (Kalra and Ahmad, 2009). Drought signatures are closely related to the spatial and temporal variability of soil moisture (Tang and Piechota, 2009). Soil water content reflects the recent precipitation, agricultural potential, and water storage and can serve as a good index of drought (Sheffield et al., 2004; Cosh et al., 2008).

Soil moisture is an important variable for understanding the hydrology and climate. It is an integral part of water and energy balance equations in atmospheric and hydrologic models. Microwave remote sensing with its sensitivity to dielectric properties is useful in mapping the land surface soil moisture (Schmugge, 1983; Behari, 2005; Pulliainen et al., 1998; Baup et al., 2007). Its dependence on spatial and temporal variability of surface dielectric constant is useful to monitor soil moisture at basin scales. Recent research

Published by Copernicus Publications on behalf of the European Geosciences Union. 
directions indicate rising interest in the operational measuring and monitoring of the global soil moisture using remote sensing (Njoku et al., 2003; Moran et al., 2004; Wagner et al., 2007). National Aeronautics and Space Administration plans to launch a dedicated soil moisture mapping mission called Soil Moisture Active Passive (SMAP) in 2012 (Barrett et al., 2009). A similar mission called Soil Moisture and Ocean Salinity (SMOS) has been successfully launched by European Space Agency in 2009 (Drinkwater and Kerr, 2009). Thus, it is important to further expand the hydrological applications of the microwave remote sensing data.

Microwave backscatter $\left(\sigma^{\circ}\right)$ depends on soil moisture and vegetation conditions of land surface. Decoupling the effects of soil and vegetation on backscatter poses a major difficulty for useful application (Magagi and Kerr, 1997; Woodhouse and Hoekman, 2000). The presence of vegetation reduces $\sigma^{\circ}$ sensitivity to soil moisture. Vegetation is sparse in arid and semi-arid regions and thus, backscatter measurements in such areas primarily depend on the soil moisture and soil roughness characteristics. Various theoretical and empirical models have been devised to retrieve soil moisture from active and passive remote sensing data (Ulaby et al., 1982; Fung, 1994; Wen et al., 2003; Bindlish et al., 2003; Paloscia et al., 2001). Theoretical models involve complicated scattering phenomena from probabilistic models of soil, vegetation, and terrain. They model plant leaves as thin disks, branches and trunks as cylinders, and soil surface by the standard deviation and correlation length of surface height (Ferrazzoli et al., 1991, 1997; Shi et al., 1997; Rahman et al., 2008; Kurum et al., 2009). Generally, such models are computationally intensive and difficult to implement in large scale applications. Empirical models of backscatter $\left(\sigma^{\circ}\right)$ are data driven and can be implemented with relative ease given sufficient in-situ data for calibration and validation.

The Tropical Rainfall Measuring Mission (TRMM) Precipitation Radar (TRMMPR), initially designed to measure rainfall (Kummerow et al., 1998; Kozu et al., 2001), provides $\mathrm{Ku}$-band $\mathrm{HH}$ polarization $\sigma^{\circ}$ measurements of the land surface. Earlier studies on TRMMPR $\sigma^{\circ}$ have shown it to be sensitive to the surface soil moisture (Seto et al., 2003; Narayan et al., 2006), but no comprehensive method has been developed for a systematic retrieval of soil moisture spatial maps from TRMMPR Ku-band data. Generally, Ku-band radiation is attenuated by the vegetation canopy but we conjecture that in the arid regions, due to sparse and shrubland-like vegetation, it has primary dependence on soil characteristics. The purpose of this study is to investigate the relationship between TRMMPR Ku-band backscatter, surface soil moisture, and vegetation in semi-arid areas. In-situ soil moisture data is not widely available and is sparse for regional scale modeling (Tang and Piechota, 2009). Soil moisture experiments (SMEX) have considerably helped in the development of remote sensing of soil moisture but the soil moisture measurements from these experiments are only available for a few selected locations (Das et al., 2008). Simulated soil moisture spatial maps from the basin scale hydrological models can fill this gap for the purposes of calibration and validation.

Generally, backscatter at C- and L-bands has better sensitivity to soil moisture than Ku-band due to relatively lesser attenuation by vegetation stand (Ulaby et al., 1982). C-band ERS scatterometer data has been used to map soil moisture in Canadian prairies (Wagner et al., 1999). Kim and Zyl (2009) have shown the use of L-band radar data to retrieve soil moisture for bare soils and vegetated areas (Kim and Zyl, 2009). The potential of Ku-band microwave to measure soil moisture has been demonstrated in several studies (Ringelmann et al., 2004). European Remote Sensing SAR data over agriculture fields have been shown to retrieve leaf area index and soil moisture under lower vegetation conditions (Moran et al., 1998). A similar study compared soil moisture retrieval from agricultural fields using $\mathrm{C}$ - and multiangle $\mathrm{Ku}-$ band SAR data for different surface roughness conditions (Sano et al., 1998). In recent studies, Ku-band backscatter data measured by Seawinds scatterometer has been shown to be temporally consistent with the changes in measured soil moisture (Mladenova et al., 2008, 2009). In a previous study, authors have used a machine learning approach to demonstrate the relationship between soil moisture and TRMMPR Ku-band backscatter data (Ahmad et al., 2010). Future missions of SMAP and SMOS operating in L-band would provide data with better sensitivity to soil moisture. Meanwhile, over arid regions with low vegetation, it would be beneficial to understand $\sigma^{\circ}$ and its $\theta$-response in relation to soil moisture at basin scale. TRMMPR Ku-band data provides an opportunity to study backscatter relationship to soil moisture at moderate spatial resolution and low to moderate vegetation cover. TRMM has been observing tropical regions for a decade and can contribute in the understanding of global hydrology by providing moderate resolution soil moisture maps of the arid regions.

In this paper, TRMMPR Ku-band $\sigma^{\circ}$ dependence on soil water content $\left(m_{s}\right)$ is investigated in the arid region of Lower Colorado River Basin (LCRB). Backscatter, in decibels (dB), is modeled as a function of $\theta, m_{s}$, and Normalized Difference Vegetation Index (NDVI); and calibrated using known soil moisture data. $\sigma^{\circ}$ model is calibrated using 1998 data and used to derive $m_{s}$ during later years. Known data consists of simulated soil moisture data from hydrologic modeling and measured data from ground stations. Simulated $m_{s}$ is estimated for top $10 \mathrm{~cm}$ soil layer by Variable Infiltration Capacity (VIC) model (Liang et al., 1994; Tang and Piechota, 2009) whereas measured $m_{s}$ is acquired for top $5 \mathrm{~cm}$ soil layer at ground measuring stations in Walnut Gulch Experimental Watershed (WGEW). Soil moisture derived from $\sigma^{\circ}$ model is validated using in-situ measurements and climate division monthly average precipitation data. The results show the potential of Ku-band instruments over arid and semi-arid regions.

This paper is organized as follows. Section 2 provides details of the study area and data. This is followed by the 
description of the research approach and methods in Sect. 3. $\sigma^{\circ}$ model, model parameters, and model calibration are also discussed in this section. Section 4 presents the results and discussion. The model derived soil moisture and the comparison with the time series of measured soil moisture and precipitation data is also presented. The spatial distribution of soil moisture in LCRB is derived and compared to the VIC $m_{s}$ estimates. Finally, in Sect. 5 conclusions are presented.

\section{Study area and data}

This section describes the characteristics of the study area and the data used in this investigation. The TRMMPR sensor specifications and NDVI data characteristics are provided. VIC model development to produce simulated soil moisture is also described.

\subsection{Colorado river basin}

Colorado River basin provides water supply, flood control, and hydropower to a large area of the southwest United States. The basin drains an area of 637000 square kilometers (246000 square miles), including parts of seven western US states, Wyoming, Colorado, Utah, New Mexico, Nevada, Arizona, and California. It is the most important basin in terms of water supply for 25 million people within the basin states and adjoining areas.

Two main mountain ranges, the Rocky Mountains and the Wasatch Mountains, border the east and the west of the basin. The basin contains large variations in topography, climate, soils, and vegetation. Elevations range from $1400 \mathrm{~m}$ to about $3700 \mathrm{~m}$. The geologic parent materials provide a wide variety of soils producing vegetation from needle leaf forest complexes to mostly desert shrubs and grasses. In general, the semi-arid region of LCRB has inhomogeneous and sparse vegetation cover with mixture of vegetation and bare soil patches. Because of its geographic and climatologic characteristics, the Colorado River Basin is particularly vulnerable to severe and sustained drought.

Figure 1 is the $\sigma^{\circ}$ image of the LCRB at $10^{\circ}$ incidence angle $(\theta)$ prepared from backscatter observations from multiple orbits. It is noted that in this paper $\theta$ is used to denote incidence angle and not soil moisture as conventionally done in the Journal of Hydrology and Earth System Sciences publications. The relationship between $\sigma^{\circ}$ and $\theta$ is non-linear over the whole range of incidence angles but is approximately linear within $3^{\circ}-15^{\circ}$. This angle range is used for the normalization to $10^{\circ}$. Due to orbital geometry of TRMM, $36^{\circ} \mathrm{N}$ latitude is the upper limit of TRMMPR spatial coverage. The dark area in the east central LCRB is the Coconino forest along the Mogollon ridge and the brighter areas in the image correspond to desert and low vegetation. Corresponding NDVI image is also provided showing predominantly low vegetation cover. Figure 1 also shows the locations of study
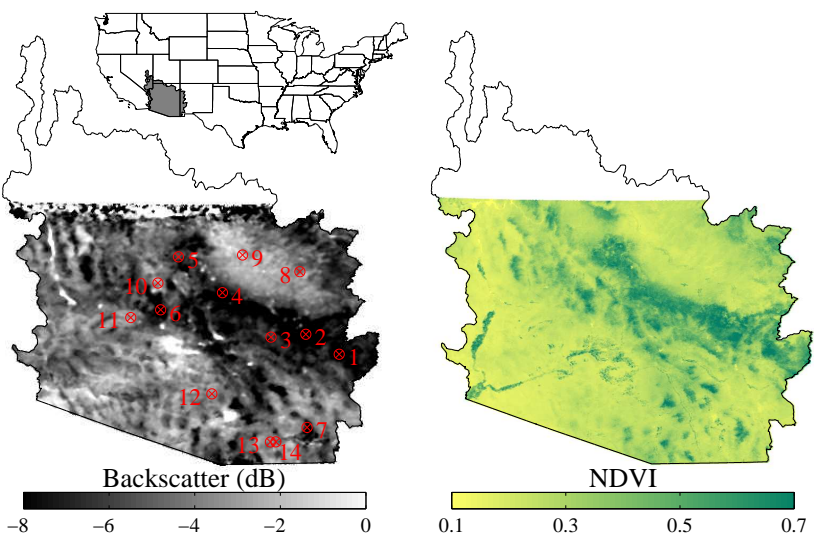

Fig. 1. Backscatter map of the Lower Colorado River Basin showing locations of study sites used in this research. Basins geographical position in the US is also shown and bounded within $31^{\circ}-40^{\circ} \mathrm{N}$ latitudes and $107^{\circ}-116^{\circ} \mathrm{W}$ longitudes. Northwest basin area is not covered by TRMM satellite. (Right) Corresponding vegetation (NDVI) map of the basin.

sites over which the $\sigma^{\circ}$ relationship to soil moisture is analyzed. In general, the semi-arid region of LCRB has inhomogeneous vegetation cover with mixture of vegetation and bare soil patches. Since TRMMPR Ku-band $\sigma^{\circ}$ over vegetated area is greatly affected by the canopy scattering we perform our analysis over three different vegetation conditions specified by the NDVI values. In the later text, dense, moderate, and low vegetation are denoted by $D V, M V$, and $L V$, respectively. The NDVI ranges for $L V, M V$, and $D V$ are $0.2-0.3,0.3-0.5$, and $0.5-0.75$, respectively. Sites $1-3$ and 4-5 are covered by $D V$ and $M V$ of Coconino forest, respectively. Locations 8-9 are in the desert north of Coconino forest and are covered with $L V$, primarily, sparse shrubs. Sites 6-7 and 10-12 are locations corresponding to $D V$ and $L V$, respectively, in other parts of the basin. Sites 13 and $14(L V)$ are the locations of gages in the WGEW where top $5 \mathrm{~cm}$ soil moisture measurements are used to validate the TRMMPR derived soil moisture. The leaf area index (LAI) value ranges for the selected sites with vegetation covers $L V, M V$, and $D V$ are $0.08-0.53,0.22-1.38$, and $0.55-2.20$, respectively. The range of values represent the seasonal variations of the vegetation cover reflected in LAI. In general, the LCRB presents an area with relatively low leaf area index.

In order to evaluate consistency of derived soil moisture to the climatic conditions, it is compared with the climate division precipitation data. Climate divisions are regions with relatively homogeneous large-scale climate patterns. The National Climate Data Center has used boundaries of the US counties, river basins, and major crop areas along with the regional climate statistics to divide US region into climate divisions. These divisions are used as a guide for local analyses and forecasting; and large-scale climate pattern analysis 
(Guttman and Quayle, 1996). Sites 1-3 (DV), 4-5 (MV) and 8-9 $(L V)$ are in climate division 7 of the state of Arizona and are used for this comparison.

\subsection{TRMM precipitation radar}

TRMM has proved to be a milestone in advancing the understanding of global rain in relation to the hydrologic cycle and climate. The TRMMPR, primarily designed to estimate vertical profile of rain from the path integrated attenuation of the radar pulse, also provides surface $\sigma^{\circ}$ measurements (Kummerow et al., 1998; Kozu et al., 2001). These $\sigma^{\circ}$ measurements have been used to study vegetation (Stephen and Long, 2002; Satake and Hanado, 2004), deserts (Stephen and Long, 2005), and ocean winds (Li et al., 2004). TRMMPR provides $\mathrm{Ku}$-band $\mathrm{HH}$ polarization $\sigma^{\circ}$ measurements. Earlier studies on TRMMPR $\sigma^{\circ}$ have shown it to be sensitive to the surface soil moisture (Seto et al., 2003; Narayan et al., 2006). This study is the first attempt in a systematic spatial estimation of soil moisture from TRMMPR backscatter data.

TRMMPR $\sigma^{\circ}$ measurements are made at $\theta$ range of $0^{\circ}-$ $17^{\circ}$. $\sigma^{\circ}$ measurements for $\theta$ less than $3^{\circ}$ have high noise. Each TRMMPR measurement record provides a rain flag indicating the precipitation condition for its $\sigma^{\circ}$ value. $\sigma^{\circ}$ corrupted by rain provides uncertain information about the land surface and thus TRMMPR $\sigma^{\circ}$ is cleaned by removing the rain contaminated and near-nadir high noise measurements. TRMMPR measurements are available at four azimuth angles (from ascending and descending passes and cross track scanning towards both sides of satellite path). $\sigma^{\circ}$ azimuth modulation is primarily caused by the topography (surface slope). The mean $\sigma^{\circ}$ variation due to azimuth angle over the LCRB is generally less than $2 \mathrm{~dB}$ except along the Mogollon ridge where the surface slope has higher variability. For the majority of this area, the azimuth angle dependence is negligible.

TRMMPR $\sigma^{\circ}$ observations have a ground resolution of $4.4 \mathrm{~km}$ which is reasonably large to include large fractions of bare soil in the arid regions. Thus, the $\sigma^{\circ} \theta$ dependence is primarily affected by the surface roughness. Large bare soil patches in the TRMMPR footprint significantly influence the backscatter measurements thus introducing strong soil moisture signal in the $\sigma^{\circ}$ observations.

\subsection{Normalized difference vegetation index}

The Normalized Difference Vegetation Index is the normalized difference of infrared band and red band reflectance and is useful for monitoring vegetation (Tucker, 1979). NDVI has been extensively used to assess ground vegetated land cover. This index benefits from the difference of reflectance of red and near infrared frequencies, which increases with the vegetation density. NDVI is defined as

$\mathrm{NDVI}=\frac{\mathrm{NIR}-\mathrm{RED}}{\mathrm{NIR}+\mathrm{RED}}$ where NIR and RED are the near infrared band and red band reflectance, respectively. The normalization results in NDVI values ranging between -1 and 1 where values less than 0 represent bare soil and 1 represents dense vegetation. We use NDVI data prepared from AVHRR that is available in the form of 7-day composite images at a $1 \mathrm{~km}$ ground resolution at the USGS earth explorer website (http://edcsns17.cr.usgs. gov/EarthExplorer/).

\subsection{Variable Infiltration Capacity (VIC) model}

VIC is a macro-scale water and energy balance model that uses meteorological, soil, and vegetation data to estimate gridded surface and subsurface runoff (Liang et al., 1994). In this research, we develop VIC model for the LCRB (Tang and Piechota, 2009). The meteorological data applied to the model includes gridded daily precipitation, minimum and maximum air temperature, and wind speed. We use the gridded meteorological data at $1 / 8^{\circ}$ resolution, prepared by the Surface Water Modeling group at the University of Washington (http://www.hydro.washington.edu/ Lettenmaier/Data/gridded/). The development of this data is described in (Maurer et al., 2002). The soil data includes field capacity, wilting point, saturated hydraulic conductivity, soil type, and porosity and are obtained from the State Soil Geographic Database maintained by the Earth System Science Center, Pennsylvania. United States Geological Survey (USGS) 30 arc-second digital elevation model is used as a reference for the soil layer depth (Abdulla et al., 1996). The vegetation data is the land composition at each grid cell and constitutes 14 classes. This data is available as a University of Maryland $1 \mathrm{~km}$ Global Land Cover product and is used to prepare the land cover map. The VIC model is forced by gridded precipitation, temperature, wind series, landcover type, and soil properties; and calculates the moisture fluxes for each grid cell. The soil moisture is computed for three soil layers, i.e., $0-10 \mathrm{~cm}, 10-40 \mathrm{~cm}$, and $40-140 \mathrm{~cm}$. VIC simulated soil moisture has been used for drought analysis (Sheffield et al., 2004) and related to the oceanic-atmospheric patterns (Tang and Piechota, 2009). We relate water content of the top $10 \mathrm{~cm}$ soil layer to the TRMMPR $\sigma^{\circ}$ observations. Despite the lack of TRMM coverage in the northwest part of basin, the overlap with the VIC estimated soil moisture map is sufficient to perform this analysis.

\section{Research approach and methods}

Backscatter depends upon the surface geometrical (landuse/landcover, soil type and condition, vegetation type and state, etc.) and dielectric (moisture content of vegetation and soil) characteristics. Despite the advances in using $\sigma^{\circ}$ in mapping various land parameters, soil moisture mapping is still in its early stages of development (Wagner et al., 2007). It is difficult to decouple the contributions from geometrical 


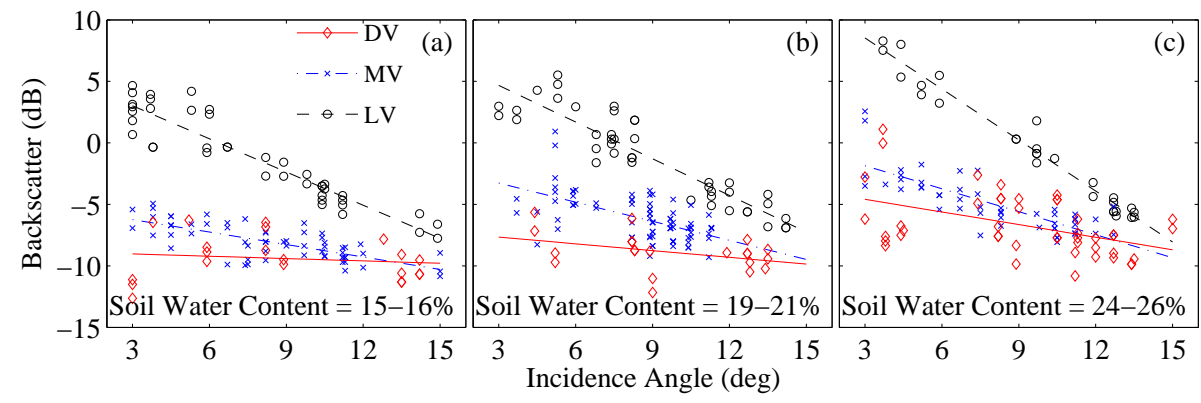

Fig. 2. Backscatter incidence angle dependence for three vegetation densities (dense, moderate, and low) and three soil water content values, i.e., (a) $15-16 \%$, (b) $19-21 \%$, and (c) $24-26 \%$.

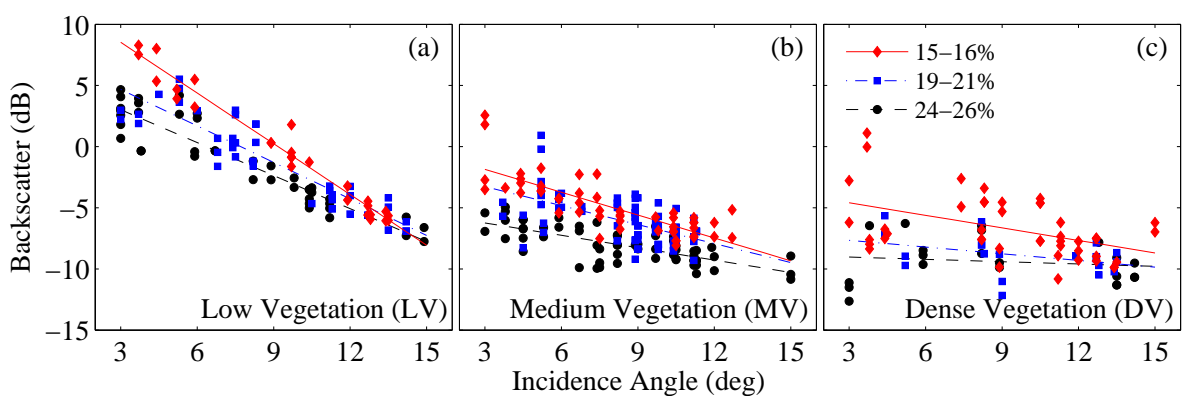

Fig. 3. Backscatter incidence angle dependence for three soil moisture ranges (15-16\%, 19-21\%, and 24-26\%) and vegetation covers, i.e., (a) LV, (b) MV, and (c) DV.

and dielectric features. These characteristics modulate the TRMMPR backscatter. $\sigma^{\circ}$ has contribution from vegetation canopy and soil, and their water content. At Ku-band, the vegetation canopy contribution is through the scattering of incident pulse by the leaves, branches, and canopy water called the volume scattering. Ku-band wavelength $(2.2 \mathrm{~cm})$ is of the order of small plant leaf sizes. Generally, plant leaves attenuate the power and this attenuation increases with increase in canopy moisture, thus poses difficulty in retrieving soil moisture characteristics from TRMMPR backscatter. Nevertheless, in arid regions where the vegetation is sparse and has large patches of intervening bare soil, $\mathrm{Ku}-$ band backscatter is directly affected by the soil moisture. In most of the LCRB, the vegetation is non-homogenous and discontinuous resulting in frequent patches of bare soil and low vegetation areas. This contributes to higher dependence of $\mathrm{HH}$-pol Ku-band backscatter on the soil surface conditions i.e., soil type, roughness, and moisture. The relative contribution of soil and vegetation scattering depends upon the vegetation cover and is reflected in the slope of the $\sigma^{\circ} \theta$ response (Long and Hardin, 1994). The relationship between $\sigma^{\circ}$ and $\theta$ is non-linear over the whole range of angles but is approximately linear within $3^{\circ}-15^{\circ}$ incidence angle range.

\subsection{Backscatter model}

Backscatter $\theta$-response varies with vegetation density and soil moisture. In order to understand the coupled dependence of vegetation and soil moisture, this section presents the analysis of $\sigma^{\circ} \theta$-response over three vegetation covers $(D V, M V$, and $L V$ ) and three soil moisture conditions (daily averages: 15-16\%, 19-21\%, and 24-26\%) (see Fig. 2). In Fig. 2 plots, each symbol point is an individual backscatter measurement at a certain incidence angle. Figure $2 \mathrm{a}, \mathrm{b}$, and c corresponds to $\sigma^{\circ}$ vs. $\theta$ plots under three soil moisture conditions. In each plot, data is shown by different symbols for three vegetation densities. Straight lines are the linear fits to each data set. The analysis of these plots reveals that soil moisture and vegetation modulate the TRMMPR $\sigma^{\circ} \theta$-response. In general, an increase in soil moisture increases $\sigma^{\circ}$ as well as the slope of $\sigma^{\circ} \theta$-response. Vegetation density has the reverse affect on TRMMPR near-nadir backscatter, i.e., as the vegetation density increases, $\sigma^{\circ}$ decreases and slope of its $\theta$-response becomes shallower. In order to further clarify the role of soil moisture in the $\sigma^{\circ} \theta$-response, Fig. 3 shows the $\sigma^{\circ}$ vs. $\theta$ plots and line fits for three soil moisture values over the three vegetation cover types. It is evident that the increase in soil moisture increases the backscatter and slope of the incidence angle response. This effect is more pronounced in the areas 
with low vegetation. Based on this analysis, we propose a coupled $\sigma^{\circ}$ model given by

$$
\begin{aligned}
\sigma^{\circ}\left(\theta, m_{s}, \mathrm{NDVI}\right) & =A+B\left(\theta-\theta_{\mathrm{ref}}\right) \\
& +C\left(\theta-\theta_{\mathrm{ref}}\right)\left(m_{s}-\mu_{s}\right)+D\left(m_{s}-\mu_{s}\right) \\
& +N\left(\mathrm{NDVI}-\mu_{\mathrm{ndvi}}\right)+e .
\end{aligned}
$$

In this model, the mean annual normalized backscatter $A$ $(\mathrm{dB})$ is modulated by the incidence angle dependence $B$ $\left(\mathrm{dB} /{ }^{\circ}\right)$, soil moisture dependence $D(\mathrm{~dB} / \%)$, coupled incidence angle and soil moisture dependence $C(\mathrm{~dB} / \% / \%)$, and NDVI dependence $N(\mathrm{~dB})$. $\theta_{\text {ref }}$ is the reference angle of backscatter incidence angle normalization and chosen as $10^{\circ}$ (Ulaby et al., 1982). $\mu_{s}(\%)$ and $\mu_{\text {ndvi }}$ are the annual averages of soil moisture and NDVI, respectively. e is the modeling error. The model takes into account $\theta$, NDVI, and $m_{s}$ dependence and provides parameters to capture backscatter response to these variables.

The model fitting is performed at the resolution of the coarsest input data, which in this case is gridded VIC soil moisture $(12 \mathrm{~km} \times 12 \mathrm{~km})$. Thus, although $\sigma^{\circ}$ is available at $4.4 \mathrm{~km}$ resolution the parameter maps and the derived soil moisture maps are made at $12 \mathrm{~km}$ spatial resolution.

The proposed model is applied to the data over the arid lands of the LCRB using the Least Squared Error Estimation (LSEE) approach. In this approach, for several (say $K$ ) observations of backscatter, incidence angle, soil moisture, and NDVI, Eq. (2) becomes a matrix equation of the form

$$
\Sigma=L p+\boldsymbol{E}
$$

where

$p=5 \times 1$ column vector of parameters

$$
\text { i.e., }\left[\begin{array}{lllll}
A & B & C & D & N
\end{array}\right]^{T}
$$

$\Sigma=K \times 1$ column vector of backscatter measurements

$L=K \times 5$ matrix where five columns correspond to the variables of the five coefficients/parameters

$\boldsymbol{E}=K \times 1$ column vector of errors,

and $[\ldots]^{\mathrm{T}}$ denotes matrix transpose. The modeling errors in the vector $\boldsymbol{E}$ are assumed to be independent identically distributed Gaussian random variables. The model can be inverted using the LSEE to compute the parameter vector given by

$$
p=L^{\dagger} \Sigma
$$

where

$$
\begin{aligned}
& L^{\dagger}=\left(L^{T} L\right)^{-1} L^{T} \text { is the pseudoinverse of } L \text { and } \\
& {[\ldots]^{-1} \text { denotes matrix inverse. }}
\end{aligned}
$$

The stability of this approach is dependent upon the invertibility of $L^{\mathrm{T}} L$. Firstly, the model performance is tested for the selected sites representing the three vegetation densities $(D V, M V$, and $L V)$. Secondly, the model is applied to all grid cells in the region to retrieve the spatial soil moisture maps.
In both model applications, the model calibration is done using 1998 data where the values of model parameters are estimated individually for each point of interest. Later, the estimated model parameter values are used to compute the soil moisture during 1999.

In order to understand the modeled backscatter dependence on soil moisture, it is necessary that the soil moisture data at desired spatial and temporal scales be available. We use the top $10 \mathrm{~cm}$ layer VIC soil moisture data to calibrate and validate the proposed backscatter model. The model is also tested for the ground measurements in WGEW.

VIC simulated soil moisture is available at $1 / 8^{\circ} \times 1 / 8^{\circ}$ grid (approximately $12 \times 12 \mathrm{~km}$ grid in LCRB region). In this study, point-based and spatial analyses of the proposed model are performed at the VIC spatial resolution, i.e., the TRMMPR $\sigma^{\circ}$ measurements within a given $12 \times 12 \mathrm{~km}$ VIC cell are used in model-parameter and soil moisture estimation. Due to coarser combined incidence angle and temporal sampling of $\sigma^{\circ}$, a ten day moving window with five day step is used for $\sigma^{\circ}$ model inversion and $m_{s}$ averaging. NDVI data ( $1 \mathrm{~km}$ resolution) is also smoothed to match the VIC resolution.

\subsection{Backscatter model calibration}

The model is applied to the three study sites with $D V, M V$, and $L V$ vegetation covers using LSEE approach and the surface fits at $\mu_{\text {ndvi }}$ are shown in Fig. 4. The corresponding model parameters are listed in Table 1. The model parameters over all the listed sites are computed using the 1998 soil water content and NDVI data.

Table 1 data reveals that $A$ decreases whereas $B$ increases with vegetation density. It is noted that $B$ values are generally negative and thus an increase in $B$ implies reduction in the physical slope of the line. $B$ depends upon the relative contribution of surface and volume scattering. Under dense vegetation conditions, $B$ can have positive values because $\sigma^{\circ}$ at near-nadir incidence angles over such land cover is lower due to higher attenuation from leaves. With an increase in the incidence angle higher backscattering is caused due to the predominant leaf orientations. This effect reduces with vegetation density. The parameters $C$ and $D$ correspond to the sensitivity to water content. The magnitudes of $C$ and $D$ reduce with increase in vegetation cover. Low $B$ values reflect low vegetation and more bare soil, thus, for low $B$ values, $C$ and $D$ are the $\sigma^{\circ}$ sensitivities to water content of soil. $N$ is the change in $\sigma^{\circ}$ per unit change in NDVI.

The model has also been used to study the impact of not using NDVI data (dropping the 5th term on the right hand side of Eq. 2). We note that adding NDVI dependence slightly improves the model performance. The reason being that the vegetation dependence of the model is also incorporated in the other parameters (especially captured in the values of $A$ and $B$ ). 

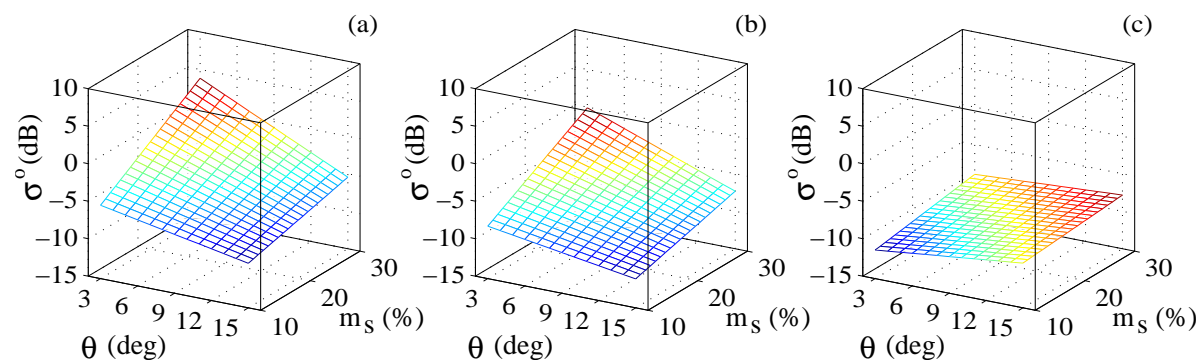

Fig. 4. Surface fit to backscatter $\left(\sigma^{\circ}\right)$ dependence on incidence angle $(\theta)$ and soil water content $\left(m_{S}\right)$ (Eq. 2) over (a) low, (b) moderate, and (c) dense vegetation.

Table 1. List of model parameters of Eq. (2) using VIC soil water content for three vegetation densities.

\begin{tabular}{lrrr}
\hline & \multicolumn{3}{c}{ Vegetation Density } \\
Parameter & Low & Moderate & Dense \\
\hline$A(\mathrm{~dB})$ & -4.88 & -7.25 & -8.77 \\
$D(\mathrm{~dB} / \%)$ & 0.29 & 0.27 & 0.08 \\
$B\left(\mathrm{~dB} /{ }^{\circ}\right)$ & -0.52 & -0.42 & 0.17 \\
$C(\mathrm{~dB} / \% / \%)$ & -0.023 & -0.017 & -0.004 \\
$\mathrm{~N}(\mathrm{~dB})$ & 6.84 & 2.16 & -3.64 \\
$\mu_{\text {ndvi }}$ & 0.27 & 0.5 & 0.67 \\
$\mu_{S}(\%)$ & 18.77 & 19.32 & 24.27 \\
RMSE $(\%)$ & 2.02 & 1.45 & 1.6 \\
\hline
\end{tabular}

The results over the selected study sites show the potential of Ku-band backscatter measurements to map soil moisture over the arid regions. In order to evaluate the applicability of this approach at a basin scale, we compute the model parameters at each grid cell in LCRB. The VIC $m_{s}$ and NDVI data at each grid cell in LCRB along with corresponding TRMMPR $\sigma^{\circ}$ measurement during 1998 are used to compute the model parameters at each grid cell. It is noted that the model described in Eq. (2) is applied individually to each grid cell and thus results in separate model parameters for at each grid cell. The spatial maps of the model parameters are shown in Fig. 5 along with root mean square error of the model fit at each point. The error is high along the Mogollon ridge due to the highly varying topography. The backscatter dependence on NDVI $(N)$ and average NDVI map during 1998 are also shown. Since the computation is grid based, the output is a spatial distribution of the model parameters.

The dense vegetation has lowest $A$ due to high attenuation of Ku-band waves by the leaves in the canopy. The bright spot in the middle of the $A$ image is from the city of Phoenix, Arizona. $A$ increases with reduction in vegetation density towards northeast and southwest. $B$ values are also consistent with the vegetation density and lows occur over the desert region where surface scattering dominates. The dense vegetation has the highest mean annual soil moisture $\mu_{s}$ that reduces over the shrubs and desert area in the northeast and southwest. $D$ measures the backscatter sensitivity to soil moisture which reduces in the areas of higher vegetation density. It has low values over the dense vegetation and high values over the desert. In the desert area, this sensitivity is also dependent upon the soil type and existence of rocky surfaces. This is evident in the image where low values of $D$ occur in the desert region. $C$ is a measure of variability in the sensitivity of soil moisture to backscatter. Even though it is linked to the relative contribution of surface and volume scattering, it is related to vegetation density and moisture. In the image, the very low values occur over the non-vegetated areas with high surface roughness. In these areas, increase in moisture will significantly alter the $\sigma^{\circ} \theta$-response from soil-surface-like-response to dense-vegetation-like-response. $\mu_{\text {ndvi }}$ is the average annual NDVI in the region whereas $\mathrm{N}$ quantifies the effect of annual change in the NDVI on $\sigma^{\circ}$ measurements.

\section{Results and discussion}

Calibrated models described in the previous section are used to compute the soil moisture during 1999. The computed model parameters from the 1998 data listed in Table 1 are used to derive soil water content from TRMMPR $\sigma^{\circ}$ data during the later years by reordering of Eq. (2), i.e.,

$m_{s}=\mu_{s}+\frac{\sigma^{\circ}-A-B\left(\theta-\theta_{\mathrm{ref}}\right)-N\left(\mathrm{NDVI}-\mu_{\mathrm{ndvi}}\right)}{C\left(\theta-\theta_{\mathrm{ref}}\right)+D}$.

Figure 6a compares the time series of TRMMPR derived and VIC estimated soil moisture during 1999 at the study site 12 . The temporal variation of the soil water content derived by the model is in agreement with the VIC estimates. The model performance deteriorates under extreme dry and wet conditions. Figure $6 \mathrm{~b}$ plots the regression lines for the study sites $1(D V), 4(M V)$, and $12(L V)$ where the $R$ is $0.57,0.66$, and 0.78 , respectively. The correlation reduces with vegetation density.

Vegetation increases the volume scattering thus decreasing the slope of $\sigma^{\circ} \theta$-response line. It depends upon the 

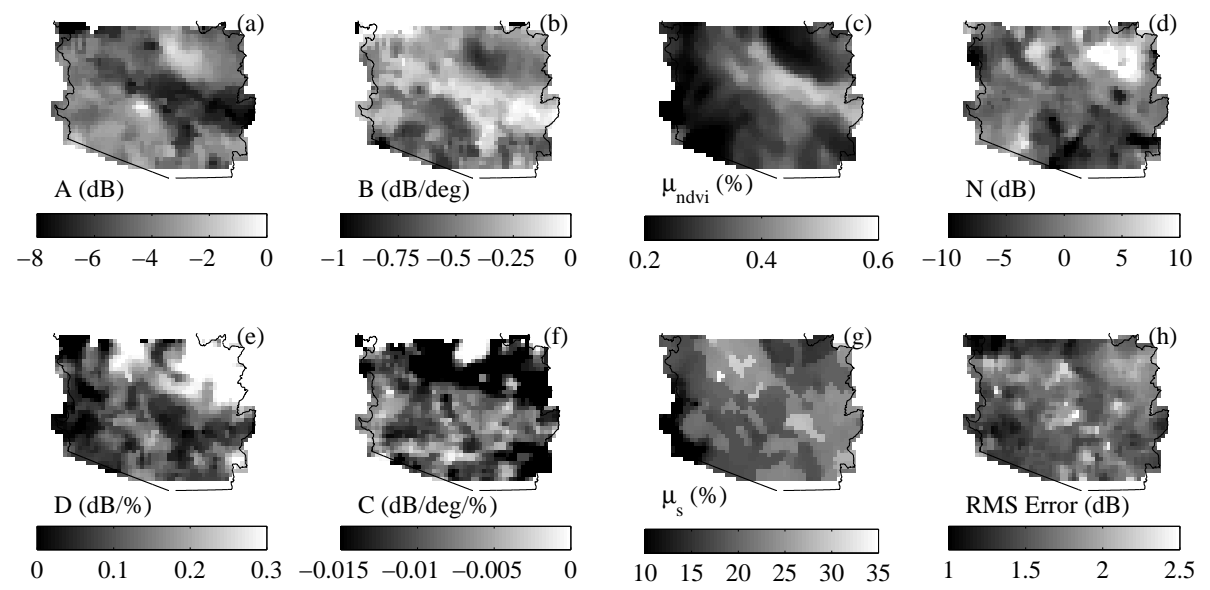

Fig. 5. Images of model parameters (a) $A$, (b) $B$, (c) $\mu_{\text {ndvi }}$, (d) $N$, (e) $D$, (f) $C$, and (g) $\mu_{s}$. (h) Root Mean Square (RMS) error image.
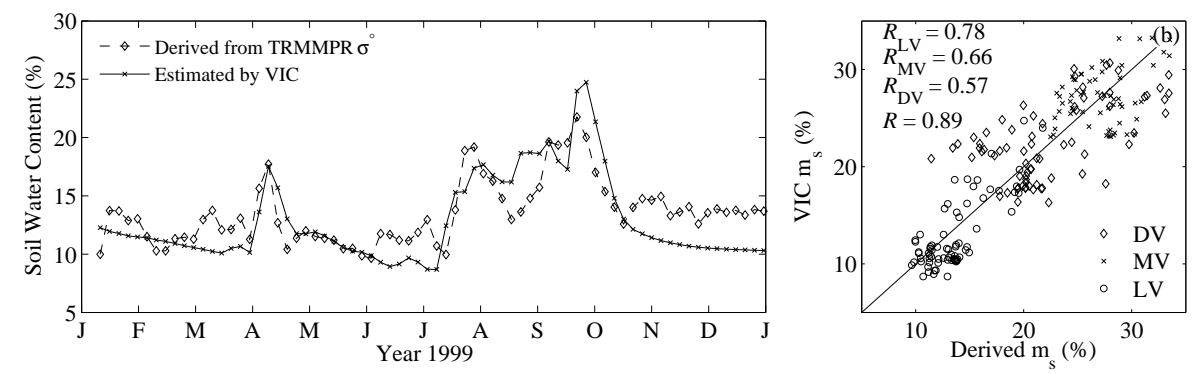

Fig. 6. (a) Comparison of 1999 temporal variation of VIC and TRMMPR derived soil water content over low vegetation area. (b) Regression analysis over three study sites, i.e., $D V, M V$, and $L V$.

characteristics of vegetation layer such as leaf area index and canopy water content. Dense vegetation attenuates the electromagnetic energy and reduces the sensitivity to the underlying soil characteristics. This effect is more severe under wet canopy conditions. The Ku-band has higher attenuation by the canopy. This significantly reduces the $\sigma^{\circ}$ values at low incidence angles thus reducing $A$ and increasing the value of $B$.

The water content increases the $\sigma^{\circ}$ and this effect is higher at low incidence angles. It results in an increase in $A$ and decrease in $B$. The $\sigma^{\circ}$ sensitivity to soil moisture depends on the vegetation cover density and vegetation water content. Over dense vegetation the soil moisture signal is overshadowed by vegetation backscatter and difficult to detect. With decrease in vegetation density the contribution from the soil increases thus raising the sensitivity to the soil water content. The presence of water in the vegetation reduces the penetration through canopy thus reducing the sensitivity to soil water content. In this case, the $\sigma^{\circ}$ is primarily reflecting the canopy water content. Under very dry conditions, the soil and vegetation have a low dielectric constant (Ulaby et al., 1982). Thus, TRMMPR backscatter is most influenced by the surface geometry.
In a similar manner, the model is also used to estimate the soil water content at study site 14 in the WGEW during 1999-2006. In this case, the results are compared to gage measurements plotted in Fig. 7a. Gage measurements during most of the year 2002 are not available. Nevertheless, the model captures quite well the temporal behavior of measured soil moisture. As seen earlier, the derived soil water content accuracy reduces under extreme dry and wet conditions. The corresponding regression line and correlation are shown in Fig. 7b. The model accuracy reduces with time since the model calibration is performed using 1998 data.

The temporal variation of soil moisture is linked to the precipitation illustrated in Fig. 8a. The time series corresponds to the climate division 7 of Arizona where monthly averages of derived soil water content are computed using the data from study sites 1-5 and 8-9 (these sites fall in this climate division). The derived soil water content provides a temporal behavior during 1999-2006 that is similar to the monthly averages of the measured precipitation data with a correlation of 0.76 (see Fig. 8b).

The analysis of derived soil water content to measured soil moisture and precipitation data confirms the potential of TRMMPR $\sigma^{\circ}$ data for soil moisture retrieval in the LCRB. The 

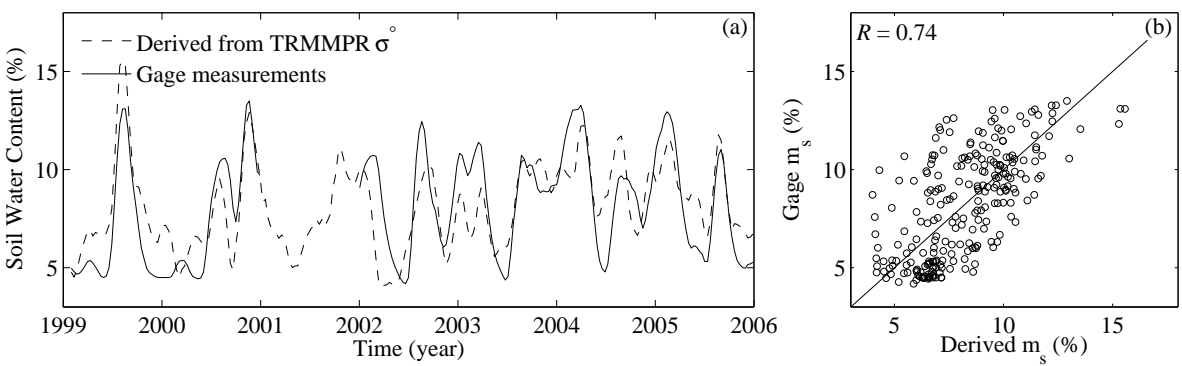

Fig. 7. (a) Comparison of TRMMPR derived and gage soil water content in Walnut Gulch Experimental Watershed. (b) Data scatter plot and correlation.
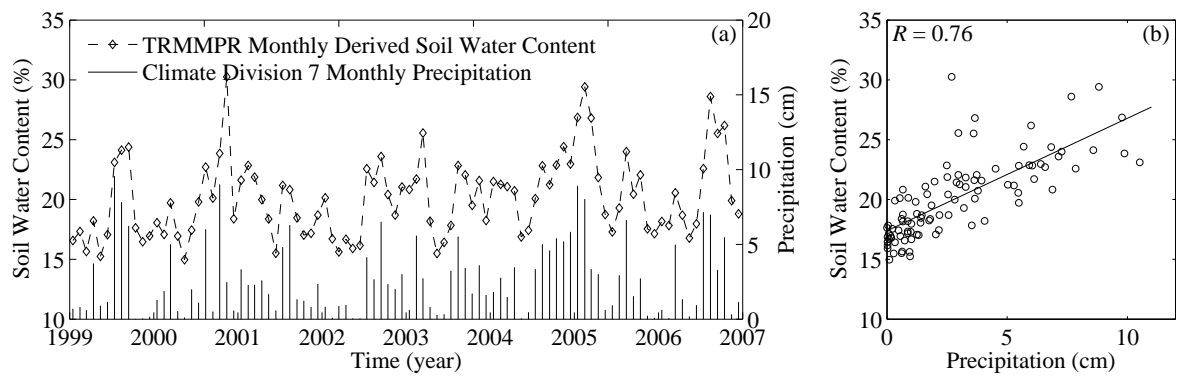

Fig. 8. (a) Comparison of TRMMPR derived soil water content and monthly average precipitation in the climate division 7 of Arizona. (b) Regression line of datasets.

proposed model captures the general temporal variation of the soil moisture. The model is able to derived soil water content over different vegetation covers in the arid region of LCRB where the sensitivity to soil moisture reduces with increase in vegetation cover.

The proposed model is point-specific and thus needs soil moisture measurements for calibration. In order to extend the model to the whole area and prepare soil moisture maps, simulated VIC soil moisture is used. As shown in Fig. 5 the model parameters are spatially coherent with the surface spatial characteristics.

The method has limited utility in areas that lack soil moisture data for calibration. Moreover, the calibration of the model is grid-point specific and thus for spatial mapping requires spatial maps of soil moisture from hydrological modeling. Nevertheless, the model has established the ability of TRMMPR Ku-band data over arid-regions for soil moisture retrieval.

Using the same approach we estimate the spatial soil moisture maps. The spatial maps of the computed model parameters (Fig. 5) are used to derive the spatial maps of soil water content from $\sigma^{\circ}$ measurements during May (dry period) and August (wet period) of 1999. Figure 9 compares the maps of model derived and VIC soil water content over the TRMM coverage of LCRB. The maps are compared during dry and wet times of the year 1999. As seen earlier in the analysis over selected study sites, the model performs better during wet season. In the wet season (August), the spatial distribution of derived soil water content is similar to the VIC estimates with $R=0.76$. The dissimilarities correspond to very dry and very wet areas of the basin. Although the correlation during dry season is lower (0.67), a general similarity in the spatial distributions is evident.

We note that the penetration depth of $\mathrm{Ku}$-band microwaves is shallow and thus only the top few millimeters (depends on the moisture) of soil layer moisture affects the backscatter measurements. Nevertheless, the surface moisture is linked to the soil moisture at near surface layers $(5-10 \mathrm{~cm})$. This is evident from the high correlation of derived soil moisture to VIC and gage soil moisture data.

We approached this study with a goal to develop a simple model that can explain relationship between backscatter and soil moisture. The proposed model is shown to provide good soil moisture estimates in LCRB and would perform well in other similar (arid and semi-arid) settings. It is difficult to decouple the impact of all surface characteristic on the backscatter measurements. The complex dependence of microwave scattering on surface roughness, soil moisture, and vegetation is simplified in a linear model that works well over mixed patches of bare soil and vegetation (typical of arid and semi-arid land surfaces) in the radar footprint. Application of the model over large basins provides good estimates of soil 

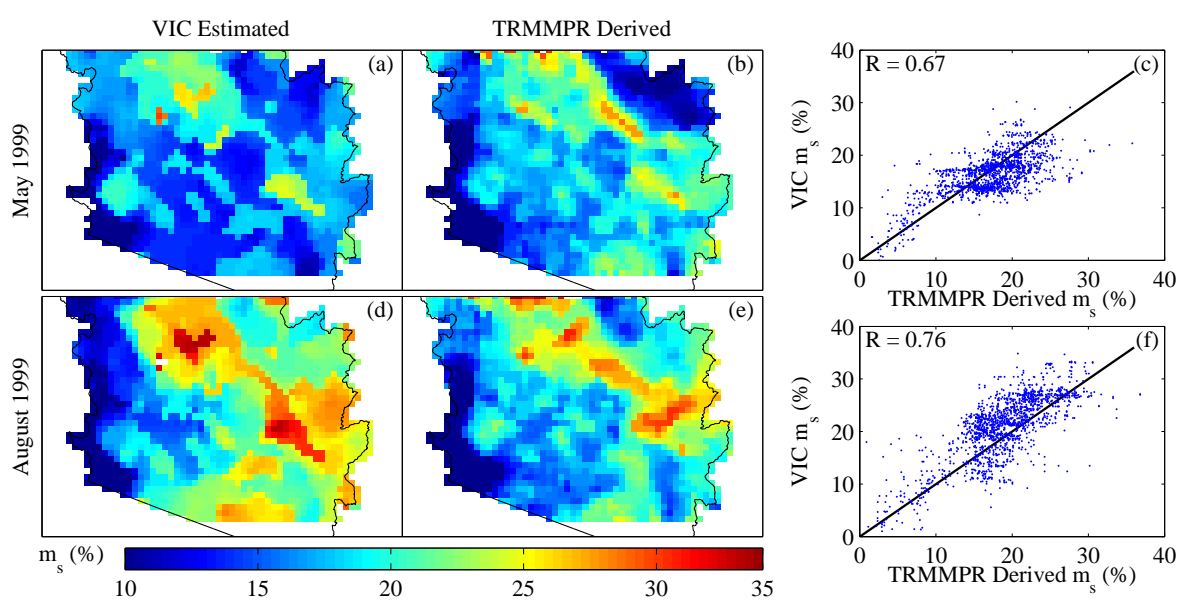

Fig. 9. Comparison of VIC (left column) and TRMMPR derived (center column) soil moisture images during dry (top row) and wet (bottom row) periods. The corresponding regression lines (right column) are also shown.

moisture without accounting for surface roughness effects. At this scale the surface roughness effect is captured in the incidence angle dependence of TRMMPR backscatter. Though desirable, explicit incorporation of surface roughness into the model would complicate the model without significantly improving the results. In regions with dense vegetation, the model performance deteriorates (as seen by reduced correlation). In such regions, the soil moisture signal at Ku-band is primarily originating from the vegetation canopy. The model performance also deteriorates under high soil moisture conditions especially if such conditions persist over several days.

\section{Conclusions}

Soil moisture is an important parameter to understand the hydrologic cycle. The soil moisture measured data is scarce and alternative approaches are needed for its spatial mapping. Radar backscatter over land depends upon the soil moisture and vegetation characteristics of the land surface. In the case of arid regions, such as LCRB, due to sparse vegetation, backscatter primarily depends on the soil moisture characteristics. A new technique that relates $\sigma^{\circ}$ response to NDVI and soil moisture data in arid regions is presented. TRMMPR $\sigma^{\circ}$ is modeled as a function of incidence angle, NDVI, and soil water content. The model calibration is performed using the known soil moisture data from VIC estimates and gage measurements; and NDVI data during 1998. The model is tested over selected study sites in the LCRB with varying vegetation cover. The model parameters reflect the surface characteristics and the $\sigma^{\circ}$ sensitivity to soil water content and NDVI. The model is used to derive the soil water content during 1999-2006 and provides results consistent with the VIC estimated and in-situ measurements. The results are temporally consistent with the time series of measured pre- cipitation data. The spatial maps of the soil water content are derived for dry and wet periods during 1999 and are consistent with the VIC estimates. The spatial coherence of these maps confirms the ability of TRMMPR to map soil moisture.

This research provides an approach to use spaceborne backscatter data for soil moisture retrieval. The model presented in the research is point-based model and provides gridded model parameters. It is a generic model with parameters that depend on surface type. The proposed model is simple yet reasonably accurate for quick retrieval of large scale soil moisture maps from backscatter data. The model inherits its spatial resolution from the input data and captures the average large scale dependence of backscatter on soil moisture and vegetation. Thus, it is suitable for studies of large scale watersheds. Due to coarse resolution of TRMMPR, the estimated soil moisture can be used in large scale hydrological and meteorological models. Finer scales $(<4 \mathrm{~km})$ may require downscaling.

The accuracy of this model reduces under extreme dry and wet surface conditions. Under very dry conditions, $\sigma^{\circ}$ is primarily a function of the surface geometry and thus does not reflect the soil water content resulting in the erroneous estimates. During very wet periods, soil saturation is the main source of errors in the estimates.

Acknowledgements. The work was partly funded by NOAA Awards NA07OAR4310324 and NA070AR4310228; NSF Award EPS-0814372; DOE Award DE-F602-08ER64709; and the Wyoming Water Development Comission. Soil Moisture data from Walnut Gulch Experimental Watershed is provided by the USDA-ARS Southwest Watershed Research Center.

Edited by: W. Wagner 


\section{References}

Abdulla, F. A., Lettenmaier, D. P., Wood, E. F., and Smith, J. A.: Application of a macroscale hydrological model to estimate the water balance of the Arkansas Red river, J. Geophys. Res.Atmos., 101, 7449-7459, 1996.

Ahmad, S., Kalra, A., and Stephen, H.: Estimating Soil Moisture using Remote Sensing Data: A Machine Learning Approach, Adv. Water Res., 33(1), 69-80, 2010.

Barrett, B. W., Dwyer, E., and Whelan, P.: Soil moisture retrieval from active spaceborne microwave observations: An evaluation of current techniques, Remote Sens.,1, 210-242, doi:10.3390/rs1030210, 2009.

Baup, F., Mougin, E., de Rosnay, P., Timouk, F., and Chênerie, I.: Surface soil moisture estimation over the AMMA Sahelian site in Mali using ENVISAT/ASAR data, Remote Sens. Environ., 109(4), 473-481, 2007.

Behari, J.: Microwave Dielectric Behavior of Wet Soils, Springer, 233 Spring Street, New York, USA, 2005.

Bindlish, R., Jackson, T. J., Wood, E., Gao, H., Starks, P., Bosch, D., and Lakshmi, V.: Soil moisture estimates from TRMM Microwave Imager observations over the Southern United States, Remote Sens. Environ., 85(4), 507-515, 2003.

Cosh, M. H., Jackson, T. J., Moran, S., and Bindlish, R.: Temporal persistence and stability of surface soil moisture in a semi-arid watershed, Remote Sens. Environ., 112, 304-313, 2008.

Das, N. N., Mohanty, B. P., Cosh, M. H., and Jackson, T. J.: Modeling and assimilation of root zone soil moisture using remote sensing observations in Walnut Gulch Watershed during SMEX04, Remote Sens. Environ., 112, 415-429, 2008.

Exploring the water cycle of the Blue planet: The Soil Moisture and Ocean Salinity (SMOS) mission, Esa Bulletin-European Space Agency 137, 6-15, 2009.

Fung, A. K.: Microwave Scattering and Emission Models and Their Applications, Artech House, Inc., Boston, Massachusetts, 1994.

Ferrazzoli P., Solimini, D., Luzi, G., and Paloscia, S.: Model analysis of backscatter and emission from vegetated terrains, Journal Electromagnetic Waves and Applications, 5(2), 175-193, 1001.

Ferrazzoli, P., Paloscia, S., Pampaloni, P., Schiavon, G., Sigismondi, S., and Solimini, D.: The Potential of Multifrequency Polarimetric SAR in Assessing Agricultural and Arboreous Biomass IEEE T. Geosci. Remote, 35(1), 5-17, 1997.

Guttman, N. B. and Quayle, R.: A historical perspective of U.S. climate divisions, B. Am. Meteorol. Soc., 77(2), 293-303, 1996.

Kalra, A. and Ahmad, S.: Using oceanic-atmospheric oscillation for long lead time stramflow forecasting, Water Resour. Res., 45, W03413, doi:10.1029/2008 WR006855, 2009.

Kim, Y. and Zyl, J. J. v.: A time-series approach to estimate soil moisture using polarimetric radar data IEEE T. Geosci. Remote Sens., 47(8), 2519-2527, 2009.

Kozu, T., Kawanishi, T., Kuroiwa, H., Kojima, M., Oikawa, K., Kumagai, H., Okamoto, K., Okumura, M., Nakatsuka, H., and Nishikawa, K.: Development of Precipitation Radar onboard the Tropical Rainfall Measuring Mission (TRMM) satellite, IEEE T. Geosci. Remote, 39(1), 102-116, 2001.

Kummerow, C., Barnes, W., Kozu, T., Shiue, J., and Simpson, J.: The Tropical Rainfall Measuring Mission (TRMM) sensor package, J. Atmos. Ocean. Technol., 15, 808-816, 1998.

Kurum, M., Lang, R. H., O’Neill, P. E., Joseph, A. T., Jackson, T. J., and Cosh, M. H.: L-Band Radar Estimation of Forest Attenua- tion for Active/Passive Soil Moisture Inversion, IEEE T. Geosci. Remote, 47(9), 3026-3040, 2009.

Li, L., Im, E., Connor, L. N., and Chang, P. S.: Retrieving ocean surface wind speed from the TRMM Precipitation Radar, IEEE T. Geosci. Remote, 42(6), 1271-1282, 2004.

Liang, X., Lettenmaier, D. P., Wood, E. F., and Burges, S. J.: A simple hydrologically based model of land-surface water and energy fluxes for general-circulation models, J. Geophys. Res.-Atmos., 99(D7), 14415-14428, 1994.

Long D. G. and Hardin, P. J.: Vegetation studies of the Amazon basin using enhanced resolution Seasat scatterometer data, IEEE T. Geosci. Remote, 32(2), 449-460, 2005.

Magagi, R. D. and Kerr, Y. H.: Retrieval of soil moisture and vegetation characteristics by use of ERS-1 Scatterometer over arid and semi-arid areas, J. Hydrol., 188-189, 361-384, 1997.

Mladenova, I., Lakshmi, V., Jackson, T., and Walker, J.: Ku-band sensitivity to soil moisture. An evaluation study for monitoring temporal soil moisture change detection over the NAFE06 study area, Proceedings of International Geoscience and Remote Sensing Symposium, 2(1), II805-II808, 2008.

Mladenova, I., Lakshmi, V., Jackson, T., Walker, J., Long, D. G., and Richard, D. J.: An assessment of QuikSCAT ku-band scatterometer data for soil moisture sensitivity IEEE T. Geosci. Remote, 6(4), 640-643, 2009.

Moran, M. S., Vidal, A., Troufleau, D., Inoue, Y., and Mitchell, T. A.: Ku- and C-Band SAR for Discriminating Agricultural Crop and Soil Conditions IEEE T. Geosci. Remote, 36(1), 265272, 1998.

Moran, M. S., Peters-Lidrad, C. D., Watts, J. M., and McElroy, S.: Estimating soil moisture at the watershed scale with satellitebased radar and land surface models, Can. J. Remote Sens., 30(5), 805-826, 2004.

Maurer, E. P., Wood, A. W., Adam, J. C., Lettenmaier, D. P., and Nijssen, B.: A long-term hydrologically based dataset of land surface fluxes and states for the conterminous United States, J. Climate, 15, 3237-3251, 2002.

Narayan, U., Lakshmi, V., and Jackson, T.: A Simple Algorithm for Spatial Disaggregation of Radiometer Derived Soil Moisture Using Higher Resolution Radar Observations, IEEE T. Geosci. Remote 44(6), 1545-1554, 2006.

Njoku, E. G., Jackson, T. J., Lakshmi, V., Chan, T. K., and Nghiem, S. V.: Soil moisture retrieval from AMSR-E, IEEE T. Geosci. Remote, 41(2), 215-229, 2003.

Paloscia, S., Macelloni, G., Santi, E., and Koike, T.: A multifrequency algorithm for the retrieval of soil moisture on a large scale using microwave data from SMMR and SSM/I satellites, IEEE T. Geosci. Remote, 39(8), 1655-1661, 2001.

Pulliainen, J. T., Manninen, T., and Hallikainen, M.: Application of ERS-1 Wind Scatterometer data to soil frost and soil moisture monitoring in Boreal forest zone, IEEE T. Geosci. Remote, 36(3), 849-863, 1998.

Rahman, M. M., Moran, M. S., Thoma, D. P., Bryan, R.t, Collins, C. D. H., Jackson, T., Orr, B. J., and Tischler, M.: Mapping surface roughness and soil moisture using multi-angle radar imagery without ancillary data, Remote Sens. Environ., 112, 391-402, 2008.

Ringelmann, N., Scipal, K., Bartalis, Z., and Wagner, W.: Planting date estimation in semi-arid environments based on $\mathrm{Ku}-$ band radar scatterometer data, Proceedings of International Geo- 
science and Remote Sensing Symposium, 2, 1288-1291, 2004.

Sano, E. E., Moran, M. S., Huete, A. R., and Miura, T.: C- and Multiangle Ku-Band Synthetic Aperture Radar Data for Bare Soil Moisture Estimation in Agricultural Areas, Remote Sens. Environ., 64, 77-90, 1998.

Satake, M. and Hanado, H.: Diurnal change of Amazon rain forest $\sigma^{\circ}$ observed by Ku-band spaceborne radar, IEEE T. Geosci. Remote, 42(6), 1127-1134, 2004.

Schmugge, T. J.: Remote sensing of soil moisture: Recent advances, IEEE T. Geosci. Remote, GE-21(3), 336-344, 1993.

Seto, S., Oki, T., and Musiake, K.: Surface soil moisture estimation by TRMM/PR and TMI, in Proceedings of International Geoscience and Remote Sensing Symposium, vol. III, 1960-1962, IEEE, 2003.

Sheffield, J., Goteti, G., Wen, F., and Wood, E. F.: A simulated soil moisture based drought analysis for the United States, J. Geophys. Res., 109(D24), D24108.1-D24108.19, 2005.

Shi, J., Wang, J., Hsu, A. Y., O’Neill, P. E., and Engman, E. T.: Estimation of bare surface soil moisture and surface roughness parameter using L-band SAR image data, IEEE T. Geosci. Remote, 35(5), 1254-1266, 1997.

Stephen, H. and Long, D. G.: Multi-spectral analysis of the Amazon basin using Seawinds, ERS, NASA, Seasat Scatterometer, TRMM-PR and SSM/I, in: Proceedings of Intl. Geosc. and Rem. Sens. Symp., Toronto, Canada, vol. 5, 2808-2810, 2002.

Stephen, H. and Long, D. G.: Microwave backscatter modeling of erg surfaces in the Sahara desert, IEEE T. Geosci. Remote, 43(2), 238-247, 2005.

Tang, C. and Piechota, T. C.: Spatial and Temporal Soil Moisture and Drought Variability in the Upper Colorado River Basin, J. Hydrol., 379, 122-135, 2009.
Timilsena, J., Piechota, T. C., Hidalgo, H., and Tootle, G.: Five Hundred Years of Hydrological Drought in the Upper Colorado River Basin, J. Am. Water Resour. Assoc., 43(3), 798-812, 2007.

Tucker, C. J.: Red and photographic infrared linear combinations for monitoring vegetation, Remote Sens. Environ., 8, 127-150, 1997.

Ulaby, F., Moore, R., and Fung, A.: Microwave Remote Sensing: Active and Passive, vol. 3, Artech House, Inc., Norwood, Massachusetts, 1982.

Wagner, W., Blöschl, D., Pampaloni, P., Calvet, J.-C., Bizzarri, B., Wigneron, J.-P., and Kerr, Y.: Operational readiness of microwave remote sensing of soil moisture for hydrologic applications, Nord. Hydrol., 38(1), 1-20, 2007.

Wagner, W., Böschl, G., Pampaloni, P., Calvet, J.-C., Bizzarri, B., Wigneron, J.-P., and Kerr, Y.: Operational readiness of microwave remote sensing of soil moisture for hydrologic applications, Nordic Hydrol., 38(1), 1-20, 2007.

Wagner, W., Noll, K., Borgeaud, M., and Rott, H.: Monitoring soil moisture over the Canadian Prairies with the ERS scatterometer, IEEE T. Geosci. Remote, 37(1), 206-216, 1999.

Wen, J., Su, Z., and Ma, Y.: Determination of land surface temperature and soil moisture from Tropical Rainfall Measuring Mission/Microwave Imager remote sensing data, J. Geophys. Res., 108(D2), 805-826, 2003.

Woodhouse I. H., and D. H. Hoekman: A model-based determination of soil moisture trends in spain with ERS-scatterometer, IEEE T. Geosci. Remote, 38(4), 1783-1793, 2000. 